\title{
A CONTRIBUIÇÃO DA DANÇA DO VENTRE PARA A EDUCAÇÃO CORPORAL, SAÚDE FÍSICA E MENTAL DE MULHERES QUE FREQÜENTAM UMA ACADEMIA DE GINÁSTICA E DANÇA ${ }^{1}$
}

Ana Carla Peto Abrão ${ }^{2}$

Luiz Jorge Pedrão ${ }^{3}$

Abrão ACP, Pedrão LJ. A contribuição da dança do ventre para a educação corporal, saúde física e mental de mulheres que freqüentam uma academia de ginástica e dança. Rev Latino-am Enfermagem 2005 março-abril; 13(2):243-8.

O estudo teve por objetivo investigar os benefícios da dança do ventre para a saúde de mulheres que freqüentam uma academia de dança do interior do Estado de São Paulo. Trata-se de um estudo qualitativo. Os referenciais foram a experiência dos pesquisadores e outras literaturas da área de dança. A amostra foi constituída por 12 mulheres com faixa etária de 16 a 40 anos, que praticavam dança do ventre há mais de três meses, às quais foi aplicado um questionário com perguntas abertas. A análise foi feita por meio dos conteúdos das respostas, o que possibilitou a conclusão de que a dança do ventre é um método que traz benefícios para a educação integral e leva à valorização da vida, melhorando a saúde e a qualidade de vida dessas mulheres.

DESCRITORES: dança; saúde; saúde da mulher

\section{THE CONTRIBUTION OF BELLY DANCE TO BODY EDUCATION, PHYSICAL AND MENTAL HEALTH OF WOMEN WHO GO TO THE GYM OR DANCE}

This qualitative study aimed to examine the benefits of belly dance for the health of women who go to a gym in the interior of São Paulo state, Brazil and was based on the researchers' experience and other literature on dancing. The references were the experience of the researcher and other literature on the dance area. The sample consisted of 12 women from 16 to 40 years of age who practiced belly dance for more than three months, who received a questionnaire with open questions. The analysis of their answers demonstrated that belly dance is beneficial for an integral education that values life, improving these women's health and quality of life.

DESCRIPTORS: dancing; health; women's health

\section{LA CONTRIBUCIÓN DE LA DANZA DEL VIENTRE PARA LA EDUCACIÓN CORPORAL, SALUD FÍSICA Y MENTAL DE MUJERES OUE VAN A LA ACADEMIA DE GIMNASIA Y DANZA}

La finalidad de este estudio fue investigar los beneficios de la danza del vientre para la salud de mujeres que van a una academia de danza en el interior de la provincia de São Paulo. Se trata de un estudio cualitativo. Los referenciales fueron la experiencia de los investigadores y otras literaturas del área de la danza. La muestra fue constituida por 12 mujeres con edad entre 16 y 40 años, que practicaban danza del vientre hace más de tres meses, a las cuales fue aplicado un cuestionario con preguntas abiertas. El análisis de las respuestas demostró que la danza del vientre trae beneficios para la educación integral, que resulta en la valoración de la vida, mejorando la salud y la calidad de vida de estas mujeres.

DESCRIPTORES: danza; salud; salud de las mujeres

INTRODUÇÃO: DESPERTANDO PARA A DANÇA DO VENTRE COMO TERAPIA

\footnotetext{
${ }^{1}$ Agradecimento a Professora de Dança do Ventre Miriam Peto; ${ }^{2}$ Enfermeira, Pedagoga, Professora de Dança, Mestranda da Escola de Enfermagem de Ribeirão Preto, da Universidade de São Paulo, e-mail: peto@eerp.usp.br; ${ }^{3}$ Professor Doutor da Escola de Enfermagem de Ribeirão Preto, da Universidade de São Paulo, Centro Colaborador da OMS para o desenvolvimento da pesquisa em enfermagem, e-mail: lujope@eerp.usp.br
} 
Vivenciamos inúmeras experiências pedagógicas que indicam a abordagem da saúde mental e sobretudo sexual no âmbito da educação pela dançą ${ }^{(1-2)}$.

A dança do ventre é uma maneira clara, simples, direta e ampla para trabalhar a saúde de um grupo de mulheres. É uma prática alternativa milenar que reduz a complexidade na abordagem da sexualidade feminina ${ }^{(3)}$.

Essa dança é flexível e sistemática e permite o entendimento de conteúdos e situações diversas que ocorrem com o corpo e a mente. Visa possibilitar aprendizagem e desenvolvimento crescentes da mulher e também o trabalho da sexualidade por meio da dança ${ }^{(4)}$. Esses aspectos motivaram-nos a buscar em mulheres normais, que freqüentam uma academia de ginástica do interior do estado de São Paulo, a sua condição geral de vida após terem praticado dança do ventre por algum período de tempo.

A dança, de um modo geral, é extremamente importante como meio de diálogo, de reflexão e de possibilidades de revisão de conceitos, pois o respeito a si próprio e ao outro está presente em sua prática, que traz aprendizados que podem levar a transformações, reafirmações, concepções e princípios, na busca de uma construção mais significativa de nosso código de valores ${ }^{(5)}$.

Salientamos que nem todos nós estamos dotados de sensibilidade nos nossos movimentos (referindo-nos ao sentido mediante o qual percebemos o esforço muscular, o movimento e a posição no espaço( $)^{(6)}$. Assim sendo, praticando a dança, é possível adquirirmos sensibilidade e, conseqüentemente, uma compreensão melhor de tudo que nos cerca. Entendemos que, por meio do som da música, tratamos de refinar nosso sentido de audição; mediante a interação de cores e formas na arte, procuramos refinar nosso sentido da visão; e; mediante a dança, procuramos refinar nosso sentido cinestésico ${ }^{(6-7)}$.

Assim, estimular nossas reações sensoriaisé particularmente importante, mas como fazer isso pode constituir-se em problema, daí a necessidade de orientação para o desenvolvimento da capacidade de diferenciar uma crescente variedade de matizes mais delicadas nas sensações, ou, inclusive, uma única sensação.

Esses elementos favorecem-nos a expressão e liberação do corpo e da mente, levando à busca da auto-valorização e do sentido positivo da vida ${ }^{(3)}$.

Toda pessoa que tenha perdido o uso de um de seus sentidos estará incapacitada para refinar essa faculdade, já que não há nada que se possa refinar. 0 fato de que os outros sentidos tendem a compensar essa perda, demonstra que as sensações recebidas são resultados de uma combinação de diferentes impressões sensoriais ${ }^{(8)}$, e a dança pode ser um fator importante nessa combinação, na busca da compensação da referida perda e, ainda, da liberação das tensões acumuladas, bem como possibilita a livre expressão corporal e a expansão saudável da sexualidade humana ${ }^{(3)}$.
Dessa forma, é extremamente importante a prática da dança também no sentido educativo, já que a cinestesia (básico, junto com a contribuição de todos os outros sentidos) tem oportunidade de abrir uma porta que possibilita a auto-educação, o autoconhecimento e a autoconsciência num meio social e objetivo. Isso não será possível, porém, sem um processo consciente e uma compreensão intelectual dos elementos implicados ${ }^{(9)}$.

A sensibilidade cultivada para o movimento e sua percepção é parte necessária de nossa capacidade de nos relacionarmos com nós mesmos, com o mundo e com os outros ${ }^{(4)}$. Ao dançar, podemos experimentar relações em que se realça a consciência de si mesmo e dos demais ${ }^{(10)}$.

O sentido de prazer que a dança pode nos oferecer, ajudanos a achar harmonia e adquirir maior sentido de pertinência. Com esse fim, nosso impulso interior para o movimento deve se vitalizar e orientar-se para uma expressão plena e estruturada pela dança, em especial a dança do ventre, melhorando, assim, a saúde física e mental $^{(11-12)}$.

Essa dança, porém, não pode ser vista como um mero exercício: ela faz parte de uma tradição muito antiga, ligada ao culto da terra e do útero poderoso da deusa. Os procedimentos da dança do ventre são sérios e merecem respeito das coisas transcendentais e sagradas $^{(13-14)}$.

Conhecida há 6 mil anos, a dança do ventre surgiu, ao mesmo tempo, no Egito, na Mesopotâmia e na região do Pacífico. Pela necessidade de oferecer um ritual totalmente dedicado às deusas Isis (no Egito), Isthar e Inana (na Mesopotâmia), nos templos, durante as festas religiosas, surgiu essa dança, também usada na iniciação sexual das jovens e na preparação do parto ${ }^{(15)}$.

A dança pode ser feita por mulheres de todas as idades, não importando o tipo físico, estado civil nem a religião.

A dança do ventre é ligada ao rito de fertilidade, é a modalidade de dança que melhor simboliza a essência da criação, onde se agradecia o milagre da vida, louvando, com dança e oração, o prazer, o nascimento e a sensualidade feminina. Apesar de ter ficado conhecida como uma dança originária da Arábia, essa "nova" mania foi criada como ritual de fecundidade há sete mil anos, por sacerdotisas egípcias ${ }^{(13)}$.

Nesse tempo, era uma dança secreta e muito importante, só sendo realizada pelas altas sacerdotisas, mulheres importantes e respeitadas na cultura egípcia, sendo proibida a apresentação em público. Com o tempo, foram permitidas apresentações em palácios, e foi aí que a população tomou conhecimento da dança do ventre.

Com a invasão árabe e a conseqüente mistura de culturas, a dança do ventre foi disseminada pelos outros países, graças à tradição de viajante e mercador, do povo árabe. Como dança milenar, é uma dança profunda, não merecendo que seja vista com vulgaridade ou 
banalidade ${ }^{(14)}$.

No início, a dança do ventre era um ritual sagrado, praticado por sacerdotisas em honra ao deus Rã (SOL). Os movimentos dos braços eram inspirados nos animais, em especial o falcão, e o ventre permanecia exposto. Aintenção não era seduzir, mas, sim, exaltar as energias da criação, concentradas no útero. No século XVIII, 0 imperador francês Napoleão Bonaparte invadiu o Egito e ficou encantado com a dança do ventre ${ }^{(13)}$. Desde essa época, a dança do ventre vem se fortalecendo como prática alternativa, devido a seus vários benefícios físicos e mentais.

A dança do ventre coloca a mulher em contato com as energias positivas. É uma dança sagrada, é trabalhada e desenvolvida para sustentar as fragilidades, afagar nossos sofrimentos, realçar o brilho opaco dos nossos corações agitados pela rotina e resgatar a identidade feminina ${ }^{(15)}$

Como terapia, faz com que os movimentos dos músculos do ventre "massageiem" os órgãos internos, regulando o metabolismo e melhorando a circulação. Os movimentos são femininos e trabalham com os sete chakras (pontos energéticos do corpo): básico, sexual, emocional, cardíaco, laríngeo, intuitivo e coronário. Em uma aula de nível adiantado, perdem-se 200 cal $^{(16)}$.

Os órgãos estimulados pela dança do ventre colaboram para que a mulher aumente o gosto pela vida. A mulher passa por uma revitalização, a consciência do próprio valor cresce, desenvolvem-se senso de dignidade e auto-estima. Estando despertos, os sentidos do corpo conduzem à melhoria da saúde, beneficiando pernas e órgãos internos. A mulher sente-se valorizada depois do contato profundo com suas raízes ${ }^{(15)}$.

No plano emocional, a dança do ventre atua na transformação das emoções da mulher, incutindo, em seu ser, mais feminilidade, mais leveza, mais suavidade e beleza, ao mesmo tempo em que trabalha a confiança e a segurança. Adança trabalha o desbloqueio de sentimentos reprimidos, ajudando a mulher a liberar verbalmente seus temores, e, no plano mental, o raciocínio torna-se mais ágil, estimula a memória e favorece maior concentração da atenção, despertando a consciência para o momento ${ }^{(15)}$.

Assim sendo, entendemos que o que foi trazido até 0 momento, resultado de breve busca literária sobre a dança do ventre, pode ser traduzido em benefícios que essa dança traz às mulheres de um modo geral, e um estudo com mulheres normais submetidas a essa prática é particularmente importante, porque poderemos, por meio de suas vivências, comprovar se tais benefícios realmente ocorrem. Outros estudos poderão ser realizados futuramente, com mulheres portadoras de transtornos mentais, por exemplo, no sentido de verificação se essa dança influencia no controle de seus sintomas psicóticos. Frente a isso, apresentamos a seguir o objetivo do presente estudo.

\section{OBJETIVO}

Verificar os benefícios que a dança do ventre traz para a educação corporal, saúde física e mental, de mulheres que freqüentam uma academia de ginástica e dança.

\section{ESTRATÉGIA METODOLÓGICA}

Sujeitos e local do estudo

Participou deste estudo um grupo de mulheres com faixa etária de 16 a 40 anos, sendo cinco casadas há mais de oito anos, e sete, solteiras. O grupo freqüentou aulas de dança do ventre por um período de tempo mínimo de três meses, em uma academia de ginástica e dança do interior do Estado de São Paulo.

Procedimento

O procedimento para realização do estudo constou de informações a respeito do seu objetivo às mulheres participantes, 0 sigilo e o direito de se retirarem da pesquisa no momento em que não se sentissem mais à vontade para participar, sem nenhum prejuízo para os seus interesses na atividade que praticavam. O estudo teve seu início após sua aprovação por um Comitê de Ética em Pesquisa Envolvendo Seres Humanos.

Trata-se de um estudo qualitativo, descritivo e humanista. Foi aplicado um questionário às mulheres incluídas no estudo, e as questões são apresentadas a seguir, juntamente com as suas respostas. Antes da aplicação, o questionário fora testado em um grupo semelhante, para averiguação de sua compreensão.

As aulas de dança do ventre, a que as mulheres participantes do estudo foram submetidas, tinham freqüência de uma vez por semana, com uma hora e meia de duração, e os recursos utilizados para isso constituíram-se em uma sala ampla, aparelho de CD e músicas de dança do ventre, o que proporcionou um ambiente adequado para tal prática. As mulheres que responderam ao questionário foram aquelas que tinham, no mínimo, três meses de prática de dança do ventre. Elas responderam ao questionário na própria sala utilizada para a prática da dança do ventre, na presença da pesquisadora, e os dados foram agrupados por aproximação, por meio dos conteúdos ${ }^{(17)}$ de cada uma das respostas dos sujeitos, permitindo, assim, um diálogo com eles, com a conotação de análise. Utilizamos essa proposta pelo fato de ela permitir o estabelecimento de articulações entre os dados e os referenciais teóricos da pesquisa, respondendo a seu objetivo.

\section{DIALOGANDO COM OS DADOS}


Como era sua vida antes de praticar a dança do ventre? A

dança do ventre me animou para praticar algum esporte, fiquei mais criativa, era tímida, perdi a vergonha, minha vida era sedentária, dedicava minha vida só a meus filhos e marido. Observamos, nas falas dos sujeitos, que a dança do ventre estimula a criatividade e melhora a comunicação, contribuindo para a diminuição da timidez, traduzindo-se em um momento para a mulher pensar em si mesma. Assim sendo, podemos entender que esse tipo de dança constitui-se também em um processo terapêutico que leva a um relaxamento, sincroniza o corpo, a mente e a alma, facilita o extravasamento de energia e eleva a auto-estima, possibilitando à mulher a busca de atividades que a levam a uma sociabilidade maior ${ }^{(17)}$.

Quais os sentimentos que você tem ao praticar a dança do ventre? Muito alegre e animada, Livre, leve e solta, mais e mais relaxada, alegre, muito bem, sinto como se estivesse dançando e praticando só para mim, olhando no espelho, me distraio, me solto, saio da rotina diária, a autoestima cresce, me sinto bonita, solta, de bem com a vida, muito bem, mais leve. A maioria das mulheres relatam alegria, relaxamento e estar de bem com a vida na prática da dança do ventre, e, no plano emocional, a dança do ventre transforma as emoções, dando à mulher mais feminilidade, beleza e suavidade, mais confiança e segurança. É a chamada "descoberta do próprio corpo", que, de certa forma, leva a mulher a aceitar-se mais e, conseqüentemente, ter mais facilidade para a aceitação do outro, incluindo o próprio parceiro.

Você sentiu alguma mudança em seu corpo ao praticar a dança do ventre? O abdômen ficou definido, deu força para os músculos das pernas e do abdômen. Fiquei mais extrovertida e menos tímida, mudou bastante no meu relacionamento no amor e na amizade, perdi a vergonha, fiz mais amizades, com mais disposição, me relaciono melhor, me sinto mais feliz, feliz, meu corpo está mais modelado, desinibição, a dança do ventre despertou a vontade de aprender a dançar, muda o charme, a delicadeza, me sinto mais mulher, comecei a me dedicar mais a mim, a me sentir bem e a gostar mais do meu corpo e me sinto mais segura em meus sentimentos e relacionamentos. A tensão pré-menstrual (TPM) quase não existe mais, 0 corpo fica mais definido e a auto-estima melhora muito. Percebemos que, de um modo geral, as mulheres participantes do estudo referiram, além de mudanças no corpo, também um cuidado melhor consigo mesmas após um período de prática de dança do ventre. Isso, de certa forma, vem ao encontro do que é relatado sobre a prática dessa dança, que, no plano terapêutico, em termos físicos, proporciona uma grande melhora para as mulheres com problemas de TPM e cólicas diversas; e, no plano psíquico, auxilia na auto-estima, timidez e inibição, pois os exercícios são específicos e ligados aos padrões funcionais, trazendo grandes resultados terapêuticos. No trabalho de ondulações, que movimenta a região do abdômen até o baixo-ventre, interligam-se os movimentos de forma primordial com a região do estômago e intestinos, auxiliando, também, no processo digestivo ${ }^{(15)}$.
Como é sua disposição durante o dia após fazer dança do ventre? Ótima, a dança do ventre faz bem para o corpo e para a mente, mais solta e relaxada, nos outros dias desenvolvo outros trabalhos que me cansam e ao fazer dança do ventre relaxo fico mais disposta, pois levo uma vida de dona de casa, então aos sábados estou fazendo alguma coisa por mim, a disposição aumenta cem por cento e rendo mais, me sinto mais animada, me sinto bem, é o meu dia, acordo com disposição para vir dançar. Todas as mulheres concordam com o fato de a dança do ventre proporcionar aumento da disposição para as atividades diárias, afirmam, também, que se sentem mais relaxadas durante o dia. De certa forma, essas colocações são semelhantes a outras que dizem respeito a exercícios físicos, pois os relatos são de uma disponibilidade melhor para atividades diversas. Adança do ventre possui toda uma parte de movimentos que trabalham bastante o corpo e dizem respeito também ao condicionamento físico, daí proporcionar toda a sensação de leveza e de bem-estar ${ }^{(15)}$

Houve mudança no relacionamento com seu parceiro? Qual? - Ajudou a me soltar mais ou seja perder a vergonha de pequenas coisas que fazem a diferença, fiquei mais solta, me sinto mais alegre, isto reflete em tudo que está ao meu redor, ele pede para eu dançar para ele, sim me sinto mais solta e sensual, fiquei mais calma e ficamos mais próximos. Observamos, nesses relatos, que a dança do ventre auxilia na melhora do relacionamento com as pessoas de forma geral e, principalmente, com o parceiro. Isso porque ela proporciona um despertar para a sensualidade, permitindo que a mulher se solte mais, primeiramente para si mesma e, posteriormente, para os relacionamentos interpessoais em seu cotidiano.

Livre para se expressar sobre a dança do ventre - É uma dança maravilhosa, deixa a mulher mais sensual e segura sobre si mesma, é ótima para a saúde e para o fortalecimento dos músculos, é ótima para animar o espírito e alegrar o ambiente, É uma dança sensual que faz a gente se sentir mais solta, ela deixa mais segura sobre os movimentos tanto do corpo quanto da mente, ela é ótima, deixa de ótimo astral, eleva nossa alma com seu ritmo contagiante, é uma dança sensual, difícil de aprender, muito gostosa, gosto do sentido dos movimentos, das roupas, da alegria e da sensualidade, antes era menos acessível e agora ficou mais fácil. A dança do ventre é uma forma de expansão saudável da sensualidade e sexualidade feminina, que é importante ser satisfatória e equilibrada, pois trata-se, também, do uso desse tipo de dança na busca de uma melhor qualidade de vida. Entendemos que os momentos de pós-modernidade nos suscitam atenção especial aos aspectos da sensualidade e sexualidade feminina, enquanto profissionais da saúde, pois a educação sexual inclui toda uma parte preventiva e de conscientização, visando evitar malefícios do uso inadequado do sexo. Esses aspectos podem ser trabalhados, também, por meio da dança e, particularmente, da dança do ventre, que propicia uma aproximação da mulher com o próprio corpo e uma valorização maior deste, tornando-a menos exposta a males 
provenientes de atos imprudentes, oferecidos por situações de vida nem sempre desejadas, e a impulsos que dizem respeito apenas a um único momento. Outro aspecto a ser levantado é a ocupação saudável do tempo livre, que pode ser dedicado à prática da dança do ventre até mesmo no próprio lar, fazendo os exercícios aprendidos nas aulas ${ }^{(3)}$. Destacamos, finalmente, os aspectos lúdicos, pois, brincando, a dança do ventre pode trazer grandes contribuições à promoção da saúde integral das pessoas.

\section{CONSIDERAÇÕES FINAIS}

Observamos, pela análise das respostas dos sujeitos do presente estudo e, também, pela experiência prática, que a dança do ventre ajudou a estimular a criatividade, trabalhar a feminilidade da mulher, diminuir a timidez e as tensões pré menstruais, aumentar a auto-estima e facilitar o processo digestivo. Mostrou ser um meio saudável de obter saúde mental e facilitar a formação de vínculos afetivos. As mulheres casadas, praticantes de dança do ventre, relataram melhora no relacionamento com o marido e mais ânimo para as atividades diárias, e as solteiras relataram sensualidade, relaxamento e o corpo mais modelado. De certa forma, é consenso entre casadas e solteiras que essa dança trouxe contribuições positivas tanto para a saúde física quanto para a mental e pode ser considerada como uma estratégia para educação integral e sobretudo sexual, que estimula a valorização da vida, tanto nos aspetos individuais quanto coletivo.

A experiência da pesquisadora em dança permitiu maior aprofundamento e análise dos conteúdos, confirmando algumas afirmações estabelecidas na prática, antes do trabalho de investigação (hipóteses). Permitiu, também, descobrir o que está atrás dos conteúdos manifestos na função de dançar, indo além das aparências do que as mulheres comunicaram. As respostas das mulheres possibilitaram 0 reconhecimento de alguns benefícios que a dança do ventre traz para a saúde física e mental: os exercícios de ondulações e alongamento aumentaram a flexibilidade dos músculos das mulheres, ajudando no controle da ansiedade e outros transtornos psíquicos e melhorando, também, o processo digestivo. Os movimentos circulares e ondulados do corpo, dos braços e das mãos, com contrações e relaxamentos musculares, realizados com o auxílio de músicas de ritmos lentos e suaves, provocaram diminuição da pressão sanguínea e do ritmo respiratório, o que, possivelmente, levou essas mulheres a terem reações no metabolismo, as quais se traduziram em um meio efetivo de combate à hipertensão e à enxaqueca.

Os exercícios de dança do ventre possibilitaram 0 relaxamento do corpo, resultando numa sensação de bem-estar, o que, provavelmente, está associado à liberação de serotonina pelo organismo. Outro fato que pode estar associado à prática de dança do ventre é a própria defesa do organismo. A experiência prática de professores dessa dança e relatos de mulheres praticantes mostram que tais praticantes são menos expostas a doenças infecciosas. Isso leva ao entendimento de que esse tipo de dança alia-se ao sistema imunológico na luta contra essas doenças, incluindo, também, outras, não infecciosas, como a depressão e a ansiedade. Assim sendo, sugerimos a realização de estudos mais específicos para comprovar os resultados provenientes da experiência prática de quem ensina e dos relatos das mulheres praticantes.

\section{REFERÊNCIAS BIBLIOGRÁFICAS}

1. Peto AC. Terapia através da dança com laringectomizados: relato de experiência. Rev Latino-am Enfermagem 2000; 8(6):35-9.

2. Peto AC. Dança Educação. [Monografia]. Ribeirão Preto (SP): Centro Universitário Barão de Mauá; 1996.

3. Peto AC, Bueno SMV. A visão que os enfermeiros licenciados tem sobre a música e dança como recurso educativo no curso de licenciatura em enfermagem. [Monografia]. Ribeirão Preto (SP): Escola de Enfermagem de Ribeirão Preto/USP; 1999.

4. Peto Abrão AC, Pedrão LJ. A Contribuição da dança do ventre para a educação e saúde de mulheres que freqüentam academia. Fórum Mundial de Educação; 2003. janeiro 19-22, Porto Alegre, Rio Grande do Sul. Porto Alegre: Comitê de Organização do FME; 2003.

5. Secretaria de Educação Fundamental (BR). Parâmetros curriculares nacionais: terceiro e quarto ciclos: apresentação dos temas transversais. Brasília (DF): Ministério da Saúde; 1998.

6. Laban R. Dança educativa moderna. São Paulo (SP): Ícone; 1990. 7. Mateus LAS. A música: elemento facilitador no relacionamento interpessoal enfermeiro-cliente em sofrimento psíquico. [Dissertação]. Ribeirão Preto (SP): Escola de Enfermagem de Ribeirão Preto/USP; 1997.

8. Fux M. Dançaterapia. São Paulo: Summus; 1988.

9. Ossona P. A educação pela dança. $2^{a}$ ed. São Paulo (SP): Summus; 1988.

10. Nanni D. Dança Educação: princípios, métodos e técnicas. Rio de Janeiro (RJ): Sprit; 1995.

11. Peto AC, Sawada NO, Zago MMF. Respirando a vida através da dança com laringectomizados: relato de experiência. In: Mendes IAC, Carvalho EC, coordenadores. Comunicação como meio de promover saúde. $7^{0}$ Simpósio Brasileiro de Comunicação em enfermagem; 2000. junho 5-6; Ribeirão Preto, São Paulo. Ribeirão Preto: FIERP; 2000. 12. Peto AC, Sawada NO, Zago MMF. Terapia pela dança no Grupo de Apoio e Reabilitação à Pessoa Ostomizada - Laringectomizados (GARPO): um estudo de avaliação. $8^{\circ}$ Simpósio Brasileiro de Comunicação em enfermagem; 2002. junho 2-3; Ribeirão Preto, São Paulo. Ribeirão Preto: FIERP; 2002. p. 137.

13. Lopes M. Os benefícios que a dança do ventre proporciona a quem pratica. Tudo sobre Dança do Ventre 2000; 2:1-10. 
14. Sabongi L. Técnicas de Quadril e Véu. Workshop Inovações do Egito; 2003. março 23; Itu, São Paulo. Itú; 2003.

15. Nahid M, Takusi S. Os benefícios que a dança do ventre proporciona a quem pratica. A Milenar Dança do Ventre 2000; 1:1-82.

16. Peto AC. Comunicação como procedimento terapêutico na assistência de enfermagem. [Monografia]. Ribeirão Preto (SP): Centro Universitário Barão de Mauá; 1998.

17. Minayo MCS, Deslandes SF, Cruz O Neto, Gomes R. Pesquisa Social: teoria método e criatividade. $19^{\mathrm{a}}$ ed. Petrópolis (RJ): Vozes; 2001. 